\title{
Innovation in mining: what are the challenges and opportunities along the value chain for Latin American suppliers?
}

\author{
Beatriz Calzada Olvera ${ }^{1,2}$ (D)
}

Received: 13 July 2020 / Accepted: 20 January 2021 / Published online: 9 February 2021

(C) The Author(s) 2021

\begin{abstract}
The mining industry, considered a traditional and conservative industry with respect to innovation, finds itself at a turning point due to the increasingly complex challenges, such as declining ore grades. These challenges have created an imperative to innovate. Parallel to the above, several digital innovations are being implemented in many mining operations across the globe. Not only do these provide solutions to the existing problems but also radically transform mining processes, increasing efficiency, profitability, and the ability to comply with stricter regulations. The incorporation of mature and incipient technologies into the mining industry has opened up many opportunities for long-established firms as well as knowledge-based start-ups. This includes potential suppliers in countries where mining accounts for a significant share of the GDP but the development of productive linkages remains suboptimal, as in Latin American countries. While in recent years, some suppliers in Latin America have made important contributions to increasing innovation in the mining industry, most suppliers in the region have not been able to do so. This paper provides an overview of the innovation paradigm of the mining sector from a global perspective, i.e., how innovation processes take place in countries with a long-established technological leadership in the mining sector, such as Australia and Canada. Given the importance of suppliers in this process, a special attention is paid to innovation in various stages of the supply chain. This is in order to provide a departure point for identifying windows of opportunity for equipment and service suppliers in Latin America.
\end{abstract}

Keywords Mining $\cdot$ Latin American $\cdot$ Suppliers $\cdot$ Innovation $\cdot$ Global value chains

\section{Introduction}

The mining industry, considered a traditional and conservative industry with respect to innovation, finds itself at a turning point due to the increasingly complex challenges, such as declining ore grades and productivity levels, and a higher competition for scarce resources, among others (DurrantWhyte et al. 2015). These challenges have created an imperative to innovate. Parallel to the above, current development of digital innovations such as the Internet of Things (IoT),

Beatriz Calzada Olvera

calzadaolvera@ihs.nl

1 Erasmus Universiteit Rotterdam - Institute for Housing and Urban Development Studies (IHS), Burgemeester Oudlaan 50 Mandeville (T) Building, 14th floor, 3062, PA Rotterdam, The Netherlands

2 United Nations University-Maastricht Economic Research Institute of Innovation and Technology (UNU-MERIT),

Maastricht, Netherlands automated drones, and 3D printing are being implemented in many mining operations across the globe. Not only do these provide solutions to the existing problems but also radically transform mining processes increasing efficiency, profitability, and the ability to comply with stricter regulations.

The incorporation of mature and incipient technologies into the mining industry has created many opportunities for long-established firms and for knowledge-based startups. This includes potential suppliers in countries where mining accounts for a significant share of the GDP, but the development of productive linkages remains suboptimal, as in Latin American countries. While in recent years, some suppliers in Latin America have made important contributions to innovation in the mining industry, most suppliers have not been able to do so. Several barriers have been identified in previous studies: from lack of testing spaces for prototypes, to broader issues, such as conservative business attitudes, hierarchical governance of the value chain, and limited communication channels between mining companies and suppliers. 
The objective of this paper is to provide an overview of the innovation paradigm of the mining sector from a global perspective, i.e., how innovation processes take place in countries with a long-established technological leadership in the sector, such as Australia and Canada. Given the importance of suppliers in this process, a special attention is paid to innovation in various stages of the supply chain. This is done to provide a departure point for identifying windows of opportunity for Latin American suppliers.

The structure of this paper is as follows: The next section provides a historical perspective of countries considered leaders in terms of innovation. The third section analyzes characteristics of innovation in the mining industry - in particular, how recent changes in the organization and supply chain structures are shaping innovation in this sector. The fourth section presents a general analysis of supply-induced innovations by looking at every stage of the supply chain. The fifth section briefly reviews the opportunities and barriers that have been faced by suppliers in Latin America when attempting to integrate into global mining value chains. The sixth section provides a summary of the findings and ideas for further research.

\section{Historical perspective on developing an innovative mining sector}

Literature (de Ferranti et al. 2002; Ramos 1998; Wright and Czelusta 2003) has shown that the mining industry was an important base for industrialization and economic development in Australia, Canada, the USA, Finland, and Sweden. Even in some middle-income countries, such as Brazil and South Africa, the mining industry has led to the emergence of world-leading firms specialized in equipment (Farooki 2012; Kaplan 2012).

Besides technological learning processes, knowledgeintensive suppliers have been key for turning natural resource sectors into knowledge-based industries with strong innovation capabilities. Knowledge-intensive suppliers, from equipment manufacturers to engineering services, have also been fundamental for the competitiveness of the industry itself, and the emergence of knowledge intensive clusters (Urzua 2013).

While the development trajectories of these highly competitive clusters, or mining business ecosystems, have taken place in different contexts, it is possible to distinguish a series of conditions that incentivized and enabled the development of technological capabilities that led to innovations within this industry. Generally speaking, these are:

- Increase the profitability of low-grade mines. During the late nineteenth century, low-ore mines of copper incentivized the development of metallurgical innovations in the USA which revolutionized the copper industry (Wright and Czelusta 2004). This experience was the opposite of high-grade ore mines in Chile ${ }^{1}$. Furthermore, empirical evidence in developing countries, such as South Africa (Kaplan 2012), indicates this was an important driver for innovation in equipment suppliers.

- Labor costs and safety concerns: In the 1960s and 1970s, an important focus was placed on reducing accidents, occupational diseases, and bettering the work environment for mining workers. For this reason, both mining companies and suppliers developed several innovations related to rock blasting and excavation. Labor-saving and higher efficiency were also important incentives in the Swedish context (Taalbi 2017).

- Social and environmental regulations: Earning the license to operate has led to further innovations in Australia, Canada, and Sweden (Rosenfeld Sweeting and Clark 2000; Taalbi 2017). Environment, public safety, and local community concerns have driven the development of innovations which allow for cleaner and more energy-efficient production methods, as well as for low-impact mining and processing operations (Upstill and Hall 2006).

- Adaptation to local context: Australian mining industries were first built upon the knowledge of German and British immigrants as well as American technologies. Later, such technologies were adapted to the hot and dry weather prevailing in Australia. Innovation through adaptation has been a characteristic of the Australian industry (ScottKemmis 2013). Other policies, such as those that isolated the South African economy during the 1970s and 1980s, pushed local firms to upgrade their technical capabilities in order to supply equipment and machinery to local mines (Kaplan 2012).

- Training and R\&D centers specialized in mining and metallurgy: Although initially Australian miners were trained by American and German miners, as early as the 1870 s, Australia had its first mining specialized center, the Schools of Mines (Ballarat and Bendigo) and the Australian Institute of Mining and Metallurgy was formed in 1893 (Scott-Kemmis 2013).

Moreover, innovation in the mining industry has been more strongly driven by a problem-solving approach,

\footnotetext{
${ }^{1}$ Wright and Czelusta (2004) compare the Chile's copper industry vis-à-vis the US: "In the mid- $19^{\text {th }}$ century the Chilean industry was comparable to and probably superior to that of the US in its technological sophistication. But the supply of high-grade ores began to decline in the $1880 \mathrm{~s}$, and, in contrast to the US, Chile did not respond to this deterioration with either new discoveries or technological adaptation" (Wright and Czelusta 2004, p. 14).
} 
than by a technological or market opportunity approach, as observed in Sweden ${ }^{2}$ (Taalbi 2017).

A further consideration is the "radicalness" of innovations, which historically has played a major role in the formation and impact of highly competitive clusters. As explained by Urzua (2013), innovative clusters typically have radical innovations at their heart, and, as these radical innovations are paired with associated incremental innovations, the whole innovative cluster has pervasive effects across and beyond the sector.

Finally, most of the incentives and enabling factors discussed in this section remain relevant to today's mining industry. However, recent organizational and corporate strategy changes have modified the way in which innovation takes place. This will be discussed in the next section.

\section{Innovation drivers, trends, and stakeholders}

Since a few decades ago, the global mining industry has been under pressure, not only due to lower commodity prices, but also to more stringent environmental regulations and public opinion. Worldwide, many existing mines are maturing, resulting in the extraction of lower ore grades and longer haul distances from the mine face, ore-body replacement rates are in decline, and new mine development times are increasing (Durrant-Whyte et al. 2015). Moreover, since the early 2000s, a pronounced decrease in mining productivity has been observed across different countries and commodities ${ }^{3}$ (Lala et al. 2015; Tilton 2014). Between 2004 and 2013, global mining productivity declined $3.5 \%$ per year, even after adjusting for deteriorating ore grades; that meant that there was an overall reduction in productivity of almost $30 \%$ during the same pe$\operatorname{riod}^{4}$ (Lala et al. 2015). Last but not least, energy and water scarcity add pressure to the industry (Deloitte 2017b).

Innovation is increasingly seen by mining firms as an imperative to enhance profitability and ensure the sustainability of operations. Perez et al. (2009) discuss more broadly drivers of innovations within the natural resource industries in four categories:

- Market requirements: Public opinion and environment.

\footnotetext{
${ }^{2}$ Taalbi (2017) tested whether innovations in different industries were driven by "problems," "technological opportunities," "market opportunities," or "institutionalized search for improved performance." Results show that innovations in the mining field are particularly problem-driven. For instance, in the 1970s-1980s, many mining innovations took place as a response to work environment issues in mining operations, such as excessive dust or vibrations.

${ }^{3}$ This refers to a relatively recent trend in the mining industry. For a comprehensive discussion of short- and long-term trends and determinants of mining productivity, see Tilton (2014).

${ }^{4}$ This figure is based on productivity index developed by Lala et al. (2015). The index is calculated using the Cobb-Douglas production function and adjusts for ore grades and mine cost inflation.
}

- Market context: Globalization, outsourcing, environmental and other regulations government policy.

- Market volume: The intensification of traditional challenges, including the diminishing quality of resources.

- Science and technology (S\&T) advances: Information and communication technologies (ICTs) and new technological paradigms, such as biotech and nanotech (supplyside induced technologies).

Based on surveys conducted among mining firms in Canada, Australia, South Africa, and Latin America, the top five inducements for innovation are (in order of priority): (1) reduction of operating costs ${ }^{5}$, (2) reduction of risk, (3) safety, (4) improved asset productivity, and (5) reducing the costs of developing new assets, i.e., mines (in Canada, Australia, and South Africa); as well as improving sustainability performance and reducing the environmental footprint (in Latin America) (Deloitte 2015, 2017b).

The key role that cost reduction plays in innovation is rooted in the undifferentiated, unvarying nature of mining commodities. Regardless of the complexity of technologies involved in the process of exploration, exploitation, and postexploitation, the final product will be the same: "copper is copper, gold bullion is gold bullion." (Bartos 2007) 6 . Since there is no room for product differentiation, mining firms usually compete on the basis of price as opposed to product characteristics (Porter 1980). In turn, this implies that the industry innovates through the adoption of technologies throughout the various stages of the supply chain and, thus, it is characterized by process innovations, instead of product innovations.

Since the 1990s, the global mining industry has undergone many changes which have transformed innovation processes within this industry. The first one, the de-verticalization of the industry, has led to an increment of outsourcing: from operational maintenance to engineering and specialized services (Morris et al. 2012; Scott-Kemmis 2013; Urzua 2013). Outsourcing has become a major corporate trend in the mining sector as it is associated to a reduction in cost operations, productivity growth, and increased profitability (Campbell 1995; Urzua 2013; Zhu et al. 2001). It ranges from non-core activities (e.g., cleaning, catering, and security services) to core mining activities: from drilling, blasting, equipment performance checking to warehousing (Peterson et al. 2001).

More recently, firms had to align their productive organization to their post-commodity boom strategies in order to meet their strategic goals while reducing costs. Thus, different corporate strategies, i.e., mergers and acquisitions (M\&As),

\footnotetext{
${ }^{5}$ This includes energy costs. Energy consumption rises as mines extract ore from deeper levels (Levesque et al. 2014); thus, tackling rising costs is of particular importance for mining companies.

${ }^{6}$ However, this does not apply to all mining commodities. For instance, some metals, such as lithium, are an exception to this: the quality of lithium will be different depending on its industrial application.
} 
changes in geographical focus, and asset diversification, have resulted in a wide range of organizational patterns which depend on the specificities of each mining firm. Some mining firms have increased centralization of processing and shared service operations (e.g., technology, finance, supply, and human resource management), while others have outsourced those services to approved suppliers to ensure process standardization and cost control. Other firms are running those shared service centers with in-house talent to enhance oversight and quality. In some cases, there is even co-sourcing, which allows the mining firm to control the operational processes whereas a third party delivers the product to the end user (Deloitte 2017b). While it is hard to establish under which circumstances firms opt for a specific type of organizational structure, the prevailing trend observed in mining corporations is a higher concentration on core business activities.

Technology management and innovation strategies are no exception to this trend. First, it is important to consider that technologies in this field comprise hardware, operational procedures, organizational structures, information systems, and management practices. Mining and processing technologies include machinery and equipment (e.g., drilling, blasting, loading, and hauling equipment, etc.) and supporting technologies, such as monitoring, control, and communications systems, planning and design tools, and support services (including software). During the history of the mining industry, there have been innovations which dramatically increased productivity and reduced costs; examples include open pit mining, block caving, long wall mining, draglines, sulfide flotation, and metal leaching (Bryant 2015). In recent decades, however, most of mining innovations have consisted of improving existing technologies, without major breakthroughs.

There are several factors affecting the performance of the mining sector in terms of breakthrough innovations:

\section{Large time scale for development and extremely high costs}

First, the industry has a reputation of not committing sufficient time and resources for the research needed to bring a new technology to the market due to the extremely large time scale and costs (Filippou and King 2011). For instance, there have been very few iron smelting technologies (a form of extractive process) which have been commercialized. Dry et al. (2002) found that mining firms were put off from developing these technologies because of the large development timescale (typically more than 20 years), and the large expensive pilot phase required. Furthermore, if mining firms did not find the underlying motivation strategic enough to counterbalance the risk and cost of the exercise, they would not attempt to develop such technologies (as cited in La Nauze and Schodde 2004).

\section{Reduced profitability}

The industry's tendency to move away from high-risk enterprises (i.e., exploration, and taking new mining technologies to the market) responds, to a considerable extent, to the procyclicality of the industry and the pressure to maintain profitable margins. In recent years, the low profitability in this industry has been caused by the long-run price decline in commodities which in turn has been attributed to the downward price-cost spiral, i.e., cost reduction measures during low price times and the industry's inability to raise prices back (Filippou and King 2011). This price-cost spiral has become even more difficult to counterweight as the industry is now relentlessly focused on delivering shortterm performance, ${ }^{7}$ which severely undermines corporate investment and deters growth. (Deloitte 2017b).

Between the 1970s and the early 2000s, the extractive industry showed, on average, a relatively low level of profitability (Filippou and King 2011). Data from more recent years indicate that this still is the case: Between 2011 and 2016, the total shareholder return (TSR) in the mining sector steadily declined, with the majority of the largest mining firms registering double-digit declines in TSR growth during said period (Deloitte 2017b). Another study, which looked at the TSR of the top 55 mining companies between 2005 and 2015, found that the annual median TSR for these companies stood at 5\%, that is $2.3 \%$ lower than the average TSR for S\&P 500 companies $^{8}$ (Nieponice et al. 2016).

\section{Reduced in-house R\&D efforts}

In the past, global mining firms companies had large $R \& D$ groups; yet, as attention switched to developing a portfolio of projects closely aligned to the core business during the 1990s, large mining houses downsized their exploration and technological efforts ${ }^{9}$ (Bartos 2007; Bryant 2015; Hitzman 2002). For example, BHP and Rio Tinto closed major in-house laboratories, and Alcoa reduced staff in its Pittsburgh complex (La Nauze and Schodde 2004). By the early 2000s, three out of four major mining companies (Alcoa, Anglo American, BHP Billiton and Rio Tinto) had reduced R\&D intensity levels (Batterham 2004). To our knowledge, there is no literature showing that this trend has reversed in recent years.

Very few of the largest companies maintain in-house research groups but quite small if compared to the past (Filippou and King 2011; Lee and Prowse 2014). These groups will

\footnotetext{
${ }^{7}$ In a recent survey of over 1,000 global C-level executives and board members, $87 \%$ said they feel considerable pressure to demonstrate strong financial performance within two years or less (Deloitte 2017b).

${ }^{8}$ The median annual TSR was $31 \%$ from 2005 through 2010 but from 2010 through 2015, it plummeted to $-17 \%$ (Nieponice et al. 2016).

${ }^{9}$ Because exploration is also a high-risk activity, groups focused on exploration activities in BHP Billiton, Rio Tinto, WMC and other major firms were also significantly reduced (La Nauze and Schodde 2004).
} 
work on highly specialized technological solutions in cases where, on one side the suppliers lack incentives to develop such solutions, and on the other, the mining firm finds the transaction costs higher than the development costs of the technology itself ${ }^{10}$. Most in-house R\&D groups will focus on technological solutions to specific issues, typically of an incremental nature (Bartos 2007; Thompson 2015).

While internal research provides an excellent service to operations, efforts to develop breakthrough innovations remain too challenging to be developed through in-house research alone (Thompson 2015). As stated by a mining firm executive: "Our budgets seem to be used to solve short-term operational problems rather than to pursue long-term innovative solutions" (Deloitte 2017a, p. 23). It is estimated that the current $\mathrm{R} \& \mathrm{D}$ investment in the mining industry ranges from 0.25 to $0.6 \%$ of total revenues (Bryant 2015). Such levels are considered low, even if compared to the oil and gas industry.

\section{Consolidation as corporate strategy}

Another corporate strategy that discouraged mining firms from pursuing internal innovation efforts was consolidation - the merger and acquisition of many smaller companies into a few larger ones. Consolidation, a trend which also took off in the 1990s, has been considered the ultimate strategy for growth without the risks of exploration and $\mathrm{R} \& \mathrm{D}$, particularly when commodity prices are weak (Filippou and King 2011; Warhurst and Bridge 2003). In a consolidation process, however, the research budgets from the two merging entities are often halved, resulting in less total research expenditures (Bartos 2007).

Bryant (2015) puts forth that the mining industry's historical collective focus on short-term cost reductions, consolidation, and cooperative purchasing agreements have discouraged internal innovation efforts. Mining firms have almost exclusively acted as price-takers rather than price-makers where risk taking has been discouraged which has resulted in a poor record of $R \& D$ investments.

Indeed, if compared to other industries, such as pharmaceuticals and IT industries, the mining industry is considered low-tech ${ }^{11}$. However, the simple R\&D

\footnotetext{
$\overline{{ }^{10} \text { Kaplan (2012) }}$ describes this as the "single large purchaser" technologies: When "potential specialist suppliers will have no advantage over the development of the technology by the large firm in-house that can offset the transaction costs entailed in transferring and adapting the technology obtained from outside of the firm. There will consequently be no outsourcing to specialist suppliers. Moreover, because of the specific nature of the application there will be no advantage to the large firm becoming a supplier of the technology it has developed for application elsewhere" (Kaplan 2012, p. 428).

${ }^{11}$ According to the OECD industrial classification derived from the ISIC REV. 3 technology intensity definition, the mining industry would correspond to the low-technology group where the mean of $R \& D$ intensity is 0.3 (the mean R\&D intensity for medium-low-technology industries is 0.8$)(\mathrm{OECD}$ 2011).
}

intensity ${ }^{12}$ approach fails to consider non-R\&D expenditures, for example, engineering development, and excludes exploration activities (which involve extensive use of high-tech equipment and often innovative approaches). R\&D measures also ignore the $R \& D$ which is embodied in capital goods and intermediate inputs, i.e., contribution of new technology from other industries to the mineral industry. (Upstill and Hall 2006). Using the ratio of acquired $R \& D$ intensity, i.e., $R \& D$ embodied in capital and intermediate goods, to simple R\&D intensity, the Basic Metals and Other Metallic Mineral Products sectors rank highest of all industry sectors by this measure, with ratios of 2.85 and 2.89 (Smith 2005). A recent input-output analysis indicates that sectors of medium-high technology intensity, i.e., machinery and equipment and chemicals, are by far the most common foreign inputs for the mining industry ${ }^{13}$. Likewise, in most countries, the knowledge intensive service sector, R\&D and other business sectors, is highly linked domestically and through imports to the mining industries - especially in high-income countries (Calzada Olvera and Foster-McGregor 2018).

The mining industry, then, appears to be more prone to innovate through the adoption of technologies developed by a third-party, hence the historical importance of knowledge intensive suppliers in countries, such as Australia, Canada, and the USA. The adoption of technologies, however, is not necessarily exempt from risks. Mining is a capital-intensive activity (Gylfason 2001) and for very large investments to be acceptable, these must either have a very small range of uncertainty, or must offer a potentially high yield on investment capital (Wells 1976). Adopting a new technology is only done when the technology has been extensively used in other areas, reducing the perceived risk by miners, as this technology will be in place for many years. As Batterham (2004) explains: "In [the mining] industry, capital is a large component of [the] costs and so, once having invested, it is difficult to justify changes within a period of 5-30 years. Generally, the more fundamental the change, the longer is the time for implementation since any change must coincide with the capital cycle" (Batterham 2004, p. 97). For example, in Australia, there is a huge lag, on average 13 years, between the release of a technology and its adoption within coal operations (Barnett and Lopez 2012). This is in sharp contrast to the oil and gas industry where the faster rate of depletion and extremely

\footnotetext{
$\overline{12}$ The simple $\mathrm{R} \& \mathrm{D}$ intensity is defined as direct $\mathrm{R} \& \mathrm{D}$ expenditures as a percentage of output (OECD 2011).

${ }^{13}$ In this study, however, the aggregation for the mining sector included the extraction of minerals occurring naturally as solids (coal and ores), liquids (petroleum), and gases (natural gas).
} 
challenging extraction contexts in which it must operate has forced a more risk-taking approach (ibid).

Thus, to keep abreast of innovations, mining firms depend on specialist suppliers, especially machinery and equipment suppliers. Such suppliers have also shifted their own R\&D activities toward strictly incremental technologies and basic research has also been cut down significantly in recent years (Bartos 2007). R\&D investments of key suppliers in joint projects with the mining industry are about $1 \%$, while oil and industry industries' suppliers allocate around 3-4\% (Bryant 2015).

The industry is shifting towards a more collaborative R\&D approach (Upstill and Hall 2006). An example of this trend is BHP Billiton's long-term alliance with Caterpillar, Rio Tinto's alliance with Komatsu and Codelco's alliance with DBT (Bartos 2007). Depending on several factors, such as the type of technology to be developed, timeframe, and underlying incentives, the collaboration can take different forms, i.e., outsourcing, open-source, collaboration, and ventures. It also involves stakeholders which are part of the "business ecosystem": mining firms (major and junior), suppliers, government, industry associations, academia, and other entities, such as incubators (Monitor Deloitte 2016). There is an increasing perspective that having a highly connected ecosystem, with a collective approach to innovation, is fundamental in moving forward with innovation efforts that go beyond cutting costs, and effectively increase productivity, attain better environmental performance, and increase profitability (Bryant 2015; Deloitte 2017a; Monitor Deloitte 2016; Upstill and Hall 2006). A collaborative approach to innovation is taking place organically across the industry, but it is still incipient and usually led by the top mining companies.

\section{How does innovation take place in the industry?}

1. Acquisition. This is achieved through the adoption of the technologies embedded in suppliers' equipment services and inputs. Through long-term purchasing agreements, suppliers develop and adapt technologies to meet their standards and other technical specifications. Technology acquired must retrofit existing mines and, therefore, it is typically of an incremental nature. New technology can be typically deployed only in greenfield operations. "This is where the mining industry comes up short. If you want to upgrade a mining system, it's hard because it was never intended to be upgraded" (Lee and Prowse 2014, p. 22). Furthermore, this form of innovation, i.e., adopting technologies from suppliers, is typically dominated by large multinational companies, especially in the case of standard technologies which already benefit from economies of scale (Kaplan 2012).

2. Outsourcing. R\&D spin-offs, e.g., Outokumpu in Finland (Filippou and King 2011), high-tech suppliers, and tech- startups. Typically works towards solutions for fully disclosed problems with small testing and quick scaling up (Deloitte 2017a).

3. Open-source collaborations. It involves tech-startups, research centers, universities, and industrial organizations. Open industry forums, such as contests and hackathons, bring the benefit of reducing innovation costs and empowering stakeholders (Deloitte 2017a). The crowdsourced innovation approach has a greater risk, but the low discovery costs mitigate such risk (Bryant 2015). Other possible benefits are a shared knowledge base and the possibility of not depending on only one supplier (Scott-Kemmis 2013). Recently, large recent hackathons have been taking place from Peru to Australia (Deloitte 2017a, 2017b). The Unearthed Hackathons, for instance, are backed up by industry leaders including major mining firms and suppliers, i.e., BHP Billiton, Rio Tinto, Caterpillar. Typically, intellectual property rights are kept by developing teams.

4. Venture collaborations. Involves suppliers, universities, research centers, and even other mining firms, typically R\&D industrial alliances. For example, Rio Tinto's flagship program of "The Mine of the Future" involves a global alliance with Komatsu and more than five research centers across Australia (2012).

\section{The role of public organisms and industry associations}

It is important to acknowledge that an essential part of many collaborations involve the role of public organisms and industry associations. For instance, the Canada Mining Innovation Council is a national non-profit association that coordinates and develops research development and innovation projects and programs among 80 members - which includes government, firms, and research stakeholders. This allows for shared financial and technology adoption risk and faster development of solutions. In total, the government-led push for innovation within the Canadian mining industry involves over 3000 different funding agencies (Monitor Deloitte 2016). In Australia, the Commonwealth Scientific and Industrial Research Organization (CSIRO), almost 20 Cooperative Research Centers (CRCs) and specialized centers of universities, such as the Julius Kruttschnitt Mineral Research Center at the University of Queensland support research efforts within the mining field. Besides these research centers, there is a diverse range of organizations that support knowledge transfer, training, and exploration (Scott-Kemmis 2013). In the USA, mining-related research has been undertaken by a few other federal agencies, such as the Department of Interior, Department of Energy, Department of Defense, and the National Science Foundation (Bartos 2007). Government 
laboratories are particularly important for taking on some of the high-risk innovation activities that are not suitable for academia, startups, or small- and mid-sized enterprises (Monitor Deloitte 2016).

In conclusion, the global mining industry innovates mostly through the adoption of third-party technologies. This is in line with the industrial taxonomy of Pavitt (1984) in which natural resource sectors, including mining, are considered to be supplier dominated, i.e., suppliers are the main sources of technology (Pavitt 1984). However, now, the sector finds itself at an impasse where innovations are mostly of an incremental nature. The potential to drive breakthrough innovations in the industry requires a more systemic type of collaboration within the framework of a well-functioning business ecosystem in both developed and developing regions (Bryant 2015; Deloitte 2017a; Figueiredo and Piana 2017).

\section{Innovation along the mining supply chain}

The mining industry is no longer a vertically integrated activity where all of its phases and corresponding activities take place within the boundaries of a multinational corporation (Kaplan 2012; Scott-Kemmis 2013; Urzua 2013). A series of changes in corporate strategies, the emergence of digital transformations and other disruptive technologies, and shifts in the regulatory framework, among other factors, have led to a de-verticalization of the mining industry: "The world looks at mining as one industry, but it's really a collection of industries with different supply and demand dynamics" (Deloitte 2017 b, p. 1). The dynamics for innovation, thus, are better understood by looking at the different industries which comprise the mining industry, and that are carried out along a value chain, such as the exploration (or junior) sector, which concentrates in the early stages of the exploration phase.

The following analysis presents a general picture of the four main stages of the mining supply chain: Exploration, project development and expansions, operations, and closure. Naturally, many aspects presented here can vary greatly according to the type of mined product and context. A particular emphasis is placed on aspects concerning suppliers and supply-driven innovations, e.g., procurement and innovative technologies, as these represent the engine of innovation in the mining sector.

\section{a. Exploration}

Exploration is considered one of the riskiest stages of the supply chain, since it involves heavy investments (mostly from drilling), the use of high-technology equipment, and very highly skilled labor and services. In the postcommodity boom years, the industry has contracted substantially due to reduction of exploration investments - especially in greenfield explorations (Monitor Deloitte 2016; S\&P 2017). Most of the investments consist of near mine exploration activities and are concentrated in Canada and the USA (20\%), Latin America (28\%), and Australia (13\%) (S\&P 2017).

Exploration expenditures and discovery rates indicate that this activity is increasingly more expensive. The reason behind this is that the easiest out-cropping deposits have been already found. The rate of discovery of major deposits has remained fairly constant over the last 30 years. However, the amount spent (in constant 2002 USD) on finding them has risen significantly ${ }^{14}$ (Schodde 2003).

Considering the high uncertainty and rising costs, the exploration industry sees innovation as an opportunity or even, as a necessity (Monitor Deloitte 2016): "Few questions excite mining executives as much as this one: What if you knew exactly what was in the ground and where?" (DurrantWhyte et al. 2015, p. 5). Therefore, in this phase, the most sought-after digital solutions ${ }^{15}$ are those aimed at developing a more precise picture of the resource base.

The biggest time lag in the exploration phase is the assay process, i.e., the testing of a metal or ore to determine its ingredients and quality. Innovations in this process are meant to increase efficiency in mine planning and investor reporting (Barnett and Lopez 2012). Some activities, such as soil and outcrop geochemistry and vegetation sampling, remain highly manual and will hardly be subject to automation in the near future. However, digital technologies, which provide timely and accurate geological and environmental knowledge for risk assessment and feasibility studies, and obtaining environmental permits and other licenses, are of high relevance.

\section{b. Project development and expansions}

Mining companies typically have their large project work managed through an agreement with an engineering consulting firm. There are two prevalent types of contracts within the mining industry:

- EPCM (Engineering, Procurement, and Construction Management). This type of contract is becoming the most common within the industry. Under an EPCM agreement, the firm manages design, procurement, construction of the mine and, often, the supporting infrastructure. It provides advisory services, construction, and procurement of

\footnotetext{
${ }^{14}$ During the $1950 \mathrm{~s}$ and $60 \mathrm{~s}$, the average cost per major gold or base metals discovery was USD\$90 million. By the 1990s, this had risen to around USD $\$ 150$ million for a major base metals discovery and US\$290 million for a major gold discovery (Schodde 2003).

${ }^{15}$ Broadly speaking, digital technologies include robotics and automation, pattern recognition, digital networks, algorithms, data collection, storing and transmitting data, programming, and coding. Digital solutions encompass and/ or overlaps with other technologies, such as the Internet of Things (IoTs) mapping and geospatial tools, software and hardware, and automated drones.
} 
materials and equipment. EPCM firms are responsible for timely delivery and meeting all design specifications (March Consulting Associates 2012).

- EPC (Engineering, Procurement, and Construction). In relation to a EPCM contract, this is a more hands-off approach, as the EPC firm has full responsibility of procurement and awards and manages all contracts with suppliers.

Engineering consulting firms in this field are usually large multinational companies which work through a selected number of partners. For instance, the engineering firm Fluor is a major player in the world and many of the largest projects in Chile have been carried out by this firm. It was responsible for the engineering, procurement, construction management, and pre-commissioning of the 980 USD million project for Codelco's Gabriela Mistral mine. It also undertook projects for the Escondida Mine worth over 2 USD billion for BHP Billiton, Rio Tinto, JECO, and JECO 2 Ltd. (Fluor n.d.)

While this is a stand-alone industry with a diversified portfolio of projects, it is also heavily influenced by the commodity price environment. The EPCM/EPC industry is also considered conservative in terms of its innovation approach (Prieto 2009). The digital revolution, however, is driving engineering firms to adopt digital solutions, such as automated drones and 3D printing, to increase design quality and construction operations efficiency (Supe 2017). The approach to innovation is also moving toward a collaborative approach: For example, Bechtel, one of the largest engineering EPCM firms, launched the "Future Fund," an internal incubator which finances development of disruptive technologies, and is collaborating with academia, equipment manufacturers (Caterpillar), and design companies (Autodesk)(Bechtel n.d.a)

Many of the top firms provide specialized services for the other phases of mining. For instance, Bechtel offers services from operations and maintenance (O\&M), mineral exploration and geology, pollution control to decommissioning, remediation, and closure services (Bechtel n.d.-b). Stork, a spinoff of Fluor, specializes in maintaining, repairing, and modifying major assets and is now a major supplier to the mining industry in Colombia (Stork n.d.).

\section{iii. Operations}

This is the stage of extraction and mobilization of the resources. Typically, this stage should correspond to 20 or more years of operations. As earlier discussed, an important barrier for innovation in this stage is the tendency for conservative attitudes, i.e., risk-aversion. In underground operations, the uncertainty is higher and so are costs associated to implementing a new technology and/or the infrastructure changes necessary for its adoption; therefore, many innovations will face higher barriers (Lee and Prowse 2014). Testing prototypes can also be difficult as often mining firms do not offer facilities for this purpose. Additionally, mature mines are typically captive to old technology decisions (Bartos 2007). As a result, some innovations are unfeasible as these do not fit the current infrastructure of the mine. Finally, some managers fail to communicate the technological solutions adequately, hindering the efficacy of the procurement process (Lee and Prowse 2014).

There is a large scope for innovations in this phase, besides more productive equipment, and machinery: Digital solutions which reduce the uncertainty surrounding the resource base, optimize maintenance, material flow, and monitoring performance, reduce waste, pollution, and the use of energy resources, and improve safety. It is calculated that the potential economic impact of digital applications in operations management and equipment maintenance alone will be about 370 USD billion per year worldwide in 2025-equivalent to $17 \%$ of the projected cost base of the industry globally in 2025 (Durrant-Whyte et al. 2015).

Furthermore, in order to increase the acceptance and impact of an innovation, suppliers should be mindful of providing solutions, whose infrastructure and technologies withstand extreme weather and/or other local geographical conditions (Lee and Prowse 2014). For example, since commercial drones could not withstand the density of air due to the altitude, locally developed drones for surveillance operate in the Antamina mines in Peru (Deloitte 2017a). This is in line with the idea that certain challenges, i.e., those related to operating in a specific geography, create an important opportunity for local suppliers due to their advantage in the specific knowledge of local conditions that large multinational companies lack (Crespi et al. 2016; Pietrobelli et al. 2018). Moreover, innovations, especially those involving a digital component, must fit the existing infrastructure, as well as the technology standards, protocols, and other suppliers' equipment which are already in place (Lee and Prowse 2014).

\section{iv. Mine closure}

It is a multi-stage process that includes shutdown and decommissioning, removal of equipment, the dismantling of facilities, and the safe closure of all mine workings. This is followed by reclamation that involves earthwork and site restoration including re-vegetation of waste rock disposal areas. The final stage of mine closure is monitoring, which includes environmental testing and structural monitoring (March Consulting Associates 2012).

Relative to other phases of the mining cycle, this phase would involve the least expenditures (Lima et al. 2016). While the mining company is responsible for incorporating a closure plan into its overall plan and financing the activities it entails, specialized service providers carry out waste management, remediation, rehabilitation, and long-term monitoring. 
This is a relatively new phase which emerged as the result of environmental regulations (Katz \& Pietrobelli 2018). Mining firms invest in this stage to comply with such regulations.

Increasing requirements to remediate environmental damage, support land reclamation, restore disturbed ecosystems, and/or rehabilitate land by establishing alternative ecosystems are raising the costs involved in this phase. The industry is moving from physical remediation of pits to holistic closure and remediation (SRK Consulting 2012).

Moreover, remediation, rehabilitation, reclamation, and restoration services for permanent mine closures have a time scale which varies from months to decades - implying this could be the longest phase of the mine lifecycle. Furthermore, a growing trend is progressive closure, the practice of conducting closure activities during operations (Hiyate 2018). Raising awareness on the importance of this phase among mining firms is opening the scope for innovations aimed at efficiently managing waste, remediation, rehabilitation, and long-term monitoring activities.

A summary of the findings of this section, including stakeholders, barriers, and potential for suppliers' innovations, can be found in Table 1 in the Annex sections.

\section{Developing innovative suppliers in Latin America}

Innovation in mining, as explained, is the result of a complex business ecosystem conformed by machinery equipment manufacturers, service providers, mining and junior firms, academia, and often other organizations. In the case of Latin America, such ecosystem is still underdeveloped despite the importance of the industry. Suppliers in this region are quite heterogenous in terms of their technological and organizational capacities and most of the interactions between mining firms and suppliers can be described as transactional rather than collaborative, as exemplified by the study case of knowledge intensive suppliers in Chile (Urzua 2013).

The flagship program "World Class Supplier Program" of BHP Billiton and Codelco launched in 2009 was developed to provide solutions to operational problems of mining firms and build technological and organizational capabilities in local suppliers. The WCSP has benefited more than 100 projects, many of them with great success, and has a goal of reaching 250 suppliers by 2035 . The program has had a positive impact albeit a small one. While the program has successfully fostered innovation efforts, results in terms of scaling up and internationalization are still not evident (Navarro 2017).

A review of the existing literature on innovation in mining in Latin America confirms that the WCSP in Chile, as well as other regional efforts in the region, i.e., Peru and Brazil, face similar challenges. An important window of opportunity for local suppliers is their ability to offer innovative solutions that effectively respond to local challenges, from water shortages to high altitudes and environmental regulations. Besides this, customization is another advantage of local suppliers and it refers to the ability to adapt and optimize assets at lower costs.

This section offers a set of examples of innovative mining suppliers in Brazil, Chile, and Peru, selected to offer interesting lessons. The findings are summarized in Table 2 in the annex section. It is important to point out that these firms were not selected on the basis of any sampling procedure, and therefore, they do not represent the universe of suppliers in Latin America.

Certainly, many of the local suppliers in the region have been able to reap the benefits of their knowledge of the local context and have successfully become important players in the industry. From the study cases reviewed, some characteristics can be drawn: On one hand, many of the firms (especially equipment manufacturers) are long-established firms with good reputation and already consolidated in the local market. In some cases, these had been subsidiaries of a multinational company or mine. On the other, small young firms usually focus on niche technologies, e.g., biotechnology, and digitalbased solutions (Stubrin 2017, Molina 2018). The technologies and methods they employ are highly tailored to the local context, and not offered by any other subcontractor abroad or by the mining firm itself.

A common characteristic of these firms, regardless of their age, is their ability to reorganize themselves and develop adequate entrepreneurial skills. These are essential traits necessary to detect opportunities beyond the local context. Furthermore, the process of innovation leads to different outcomes: Suppliers which aim for customization-based services typically develop incremental innovations (Navarro 2017). Very few suppliers, usually with a long-established capacity, have been able to identify market needs to develop radical innovations (Molina 2018).

Latin American suppliers are confronted with challenges that also exist in countries with highly innovative mining ecosystems. For instance, technological lock-in, risk-aversion, conservative attitudes, and pro-cyclicality in research investments. However, some aspects negatively affect Latin American suppliers more strongly due to the weak institutional setting and limited support in key areas, such as research and training centers. As earlier explained, developing breakthrough technologies requires consistent investments which are often too large for small and medium companies to absorb (Monitor Deloitte 2016; Bartos 2007).

A major barrier often faced by local firms is the mining firms' risk-aversion to work with local suppliers. When there are high transaction costs, complexity of information, and asset specificity, mining companies prefer long-standing suppliers, which are rarely local. As Stubrin (2017) points out, mining firms' operators are loyal to international suppliers; they trust their technologies and they have been trained in 
using them. Thus, such preferences reinforce the technological lock-in. Moreover, since interaction between local suppliers and mining firms is more of a transactional nature rather than collaborative, with a hierarchical governance of the value chain often prevailing (Pietrobelli et al. 2018), innovation risks end up being absorbed almost entirely by the supplier (Figueiredo and Piana 2017; Molina 2018).

These limitations are heightened by the limited communication between suppliers and mining firms. Formal communication channels are tenders, or specific programs such as the WSCP. However, informal communication is very important as it allows suppliers to identify needs of mining firms (Stubrin 2017) - especially considering that technology needs are not necessarily adequately communicated within mining firms.

The WSCP, for instance, has created incentives for collaboration and opened communication between firms and suppliers. However, it has failed to create incentives to provide facilities for piloting and testing during the scaling up phase (Navarro 2017). Two firms in Peru, Tumi, and Resemin, used their local knowledge of the market to test their prototypes in local mines and successfully launched innovative technologies for large mining firms despite the little interactions they had (Molina 2018). While most mining firms remain conservative in this regard, some have created incentives to test new products and equipment: For instance, a major firm in Latin America has set aside a small portion of its mining sites as innovation testing grounds (Deloitte 2017a). Creating the right incentives to scale up these initiatives that provide access to this type of spaces is essential especially for younger firms.

Finally, suppliers in Latin America face issues related to market expansion, organizational learning, knowledge absorption efforts, and entrepreneurial skills. One aspect of market expansion relates to diversification, due to the dependency on high commodity prices. It is necessary for firms to diversify by finding applications in other fields. The other aspect concerns scalability and internationalization: going beyond the local specific solutions to develop a client based abroad. Molina (2018) writes that this challenge is, to a great extent, the result of scarce support from the government, educational and research centers, as well the absence of coordination channels, which are ultimately necessary for the transmission of knowledge and the establishment of a relation with mining companies.

While most of these issues are not necessarily unique to Latin America, in the Australian, American, or Canadian contexts, the existence of coordinating agencies, research centers, and other industrial organizations opens the possibility for suppliers' innovations to be realized in a systemic way, by creating spaces for communication, addressing common problems, and sharing the risk and cost for innovators (Deloitte 2016).

The reality for most Latin American suppliers is that successful innovation efforts have been done in isolation with little to no interaction with top mining firms and limited institutional support as exemplified by the cases reviewed in Brazil, Chile, and Peru. As Figueiredo and Piana (2017) conclude "innovative capability-building processes are more a result of individual entrepreneur impetuses than a consequence of deliberate corporate and/or government policies" (Figueiredo and Piana 2017, p. 11).

\section{Conclusions}

The objective of this paper was to provide an overview of how the mining industry innovates and to provide a better understanding of who are the key stakeholders and their main challenges from a global perspective. The mining industry, unlike other industries (e.g., the IT or pharmaceutical sectors), innovates through its processes because there is little space for product innovation, and producers, i.e., miners, cannot control prices. This has resulted in innovation being driven mostly by cost-cutting and regulation compliance. More importantly, the source of those innovations tends to be a wide and varied network of suppliers: It is the technology embedded in machinery, services, and other inputs that allow for innovation to occur in this sector.

Significant changes in the corporate strategy and environment within mining companies have led to substantial reductions of R\&D groups and other intramural innovation efforts, which are now largely focused on providing services to operations and are typically incremental in nature. Pressing issues and increasingly challenging conditions, such as lower ore grades, more difficulties in finding and exploiting deposits, lower productivity, and lower commodity prices, offer incentives for the adoption of digital technologies and other niche technologies along the value chain.

Likewise, all these factors contribute to a new paradigm, albeit rather incipient, in which innovation, especially of a radical type, is developed through partnerships and collaborations: From weekend hackathons to year-long projects, such as the Mine of the Future. Under this paradigm, innovation is understood as the outcome of a high-functioning business ecosystem and its benefits go well beyond the objective of cost reductions (e.g., productivity gains, expansion of the resource base, and/or a reduced environmental footprint).

The de-verticalization of the industry has resulted in an intricate collection of industries: Junior firms are specialized in exploration activities, engineering firms provide $\mathrm{EPCM} / \mathrm{EPC}, \mathrm{O \& M}$, and environmental services, and mining firms stick to a portfolio of activities closely aligned to the core business. The distinct phases along the value chain also determine, to a considerable extent, the potential barriers, and opportunities for supply-induced innovations. For instance, digital solutions aimed at deepening the knowledge surrounding the resource base have a large economic potential for exploration and operation activities. 
While the perspective of the paper is mostly global, many of the drivers and challenges for innovation hold true for the Latin American mining firms and suppliers. Thus, the limited development of knowledge intensive suppliers is explained by the fact that innovation is carried out in isolation by suppliers, who typically absorb most of the risks. Naturally, limited capabilities in some key areas, such as entrepreneurial skills and identification of external markets, are also important barriers. Overcoming challenges, such as mining companies' risk aversion, is certainly a much bigger task for local Latin American suppliers than for their Australian counterparts given the limited institutional support in Latin America.

Further research into the necessary capabilities and the stakeholders' role in each of the phase of the mining value will provide a more detailed assessment of the opportunities for Latin American suppliers. For instance, the role that $\mathrm{EPCM} / \mathrm{EPC}$ specialized firms play in the long-term procurement process of a mine remains largely understudied. Another possibility for future research relates to the technologies and capabilities local engineering services that could be integrated in exploration activities, which offer great potential for developing knowledge-based capabilities.

Acknowledgements I would like to thank Carlo Pietrobelli, Michiko Iizuka, and Fernando Vargas for their very helpful comments and suggestions. This publication was made possible thanks to the support of the Inter-American Development Bank. The opinions expressed here are those of the author and do not necessarily reflect the views of the InterAmerican Development Bank, its Board of Directors, or the countries they represent.

\section{Appendix}

Table 1 Innovation in mining: stakeholders, barriers, and potential for suppliers' innovations

\begin{tabular}{|c|c|c|c|}
\hline Phase & Stakeholders involved & Main barriers for supplier's innovations & Potential for suppliers' innovations \\
\hline Exploration & $\begin{array}{l}\text { Junior firms. These are firms specialized in } \\
\text { the exploration stage (also known as } \\
\text { junior sector). They identify potential } \\
\text { valuable extractive resources and stake a } \\
\text { claim which is later sold to a mining firm. } \\
\text { Mining firms. They acquire the right to } \\
\text { further explore and exploit the land } \\
\text { where the resources were found. Some } \\
\text { mining firms are engaged as junior firms } \\
\text { as well. } \\
\text { Knowledge-intensive service firms: } \\
\text { - Exploration specific services: } \\
\text { Geotechnical engineering, geophysics, } \\
\text { geology, drilling. } \\
\text { Other service suppliers: } \\
\text { - Transportation and logistics services (e.g., } \\
\text { rent of helicopters and other } \\
\text { transportation services). } \\
\text { - General support services (e.g., HR and } \\
\text { recruitment) }\end{array}$ & $\begin{array}{l}\text { High uncertainty. Regarding the resource } \\
\text { base and costly exploring operations. } \\
\text { Thus, innovations which imply a high } \\
\text { investment in this phase, will mostly } \\
\text { likely face more conservative business } \\
\text { attitudes. } \\
\text { Pro-cyclicality. The post-commodity boom } \\
\text { has led to lower levels of investment in } \\
\text { exploration activities - especially in } \\
\text { greenfield explorations. }\end{array}$ & $\begin{array}{l}\text { Digital solutions to deepen the } \\
\text { understanding of the resource base } \\
\text { which translates into higher probability } \\
\text { of resource discovery and better drilling } \\
\text { target operations. Examples: } \\
\text { - Ore-body models combined with blast } \\
\text { hole drill data and online sampling. } \\
\text { - Statistical techniques to process } \\
\text { exploration data. } \\
\text { Digital solutions thus are to increase } \\
\text { efficiency in mine planning and } \\
\text { investor reporting. Example: } \\
\text { - Automation of assaying processes to } \\
\text { deliver real-time results and/or any other } \\
\text { technology to reduce reliance on the } \\
\text { conventional laboratory assaying pro- } \\
\text { cess. } \\
\text { Digital solutions which provide timely and } \\
\text { accurate geological and environmental } \\
\text { knowledge for risk assessment and } \\
\text { feasibility studies, and obtaining } \\
\text { environmental permits and other } \\
\text { licenses, are of high relevance. } \\
\text { Examples: } \\
\text { - Methods which combine remote sensing } \\
\text { tools, satellite imagery and other } \\
\text { geological models to increase knowledge } \\
\text { of risk areas. }\end{array}$ \\
\hline
\end{tabular}

Project Mining firms. These provide a design plan develop- to the engineering firm and supervise the ment and delivery of the project. Depending on the expansions agreement with the engineering company, they will grant supplier contracts.

EPCM/EPC firms. Under an EPCM agreement, the firm manages design, procurement, and construction of the
Tight-knit network. EPC/EPCM firms are large multinational firms which often work with a selected group of partners. As with the rest of the industry, these firms can have conservative attitudes toward innovation. Yet, they may represent a very relevant source of contracts for local suppliers.
Digital solutions and equipment to increase design quality and construction operations efficiency and productivity, which in turn reduces costs and increases profitability, especially considering the growing geographical spread of the projects. Examples: 
Table 1 (continued)

\begin{tabular}{|c|c|c|c|}
\hline Phase & Stakeholders involved & Main barriers for supplier's innovations & Potential for suppliers' innovations \\
\hline & $\begin{array}{l}\text { mine and, often, the supporting } \\
\text { infrastructure. } \\
\text { Under an EPC agreement, firms also handle } \\
\text { supplier contracts. They are responsible } \\
\text { for timely delivery and meeting all design } \\
\text { specifications. } \\
\text { Other suppliers: } \\
\text { These are suppliers to EPCM/EPC firms } \\
\text { covering machinery, equipment, civil } \\
\text { engineering services, and general support }\end{array}$ & $\begin{array}{l}\text { Pro-cyclicality. Firms will be affected by } \\
\text { low commodity prices as in the } \\
\text { exploration phase. }\end{array}$ & $\begin{array}{l}\text { - Big data analytics for opportunity } \\
\text { management and predictive analytics for } \\
\text { operations. } \\
\text { - Drones for aerial surveys and GIS/GPS for } \\
\text { geolocation. } \\
\text { - Wearables for employee safety } \\
\text { - Augmented reality for maintenance and } \\
\text { inspection. } \\
\text { - Mobility solutions for field technicians } \\
\text { and workers. }\end{array}$ \\
\hline
\end{tabular}

Operations Mining firms. In charge of technology management and the conformation of different collaborative arrangements with suppliers and other firms. They are responsible for the procurement process, including bidding processes.

Suppliers: Equipment, machinery, and inputs suppliers. Multinational companies, specialized in equipment manufacturing, can play an important role as partners in technology management and innovation efforts (e.g., the global alliance between Rio Tinto and Caterpillar).

Knowledge intensive service firms:

- Service suppliers involved in the extractive and processing activities, such as seismicity, rock mechanics, mining engineering, blasting, metallurgy, leaching and metallurgy.

- Environmental services and general engineering services, such as O\&M services and biotechnology specialists.

Other service suppliers:

- Transportation and logistics services.

- General support services (e.g., HR, recruitment, surveillance, and cleaning, etc.)

\section{Closure Mining firms:}

Finances activities related to this stage. Ideally considers this phase since the inception of the mine design (this potentially involves EPCM/EPC firms).

Knowledge intensive service Suppliers: Specialized in environmental services, remediation, environmental engineering and acid mine drainage. Other firms offering demolition, forestation, and debris removal services.
Technological lock-in: Mature mines' infrastructure, (especially in underground mining), incompatible

protocols/standards, and other older technology decisions limit the window of opportunity for innovation. Innovative solutions therefore are not adopted because they lack cost efficiency and/or are technically unfeasible.

High uncertainty: It is higher for ore in ground activities, such as resource drilling, than for out of ground ore stages, Examples.

such as stockpiling or surveying mobile fleet. In situ prototype testing may face high barriers.

Mining firms' style technology management: In some firms, technology requirements, i.e., solutions, are not properly communicated at higher levels. This situation may hamper the bidding process.

A very high level of expertise is required from the supplier to be able to 'anticipate' such solutions. Local suppliers also often lack testing spaces in the mine.

Therefore, these needs are typically met by long-standing suppliers, or spin off companies where a trust relationship has been long established.

Relatively low expenditure: This phase involves the least expenditures relative to other phases of the mining cycle. The concept itself is relatively new but expanding.

Mixed performance: Despite the increasingly strict regulations and public awareness, there are companies which do not prioritize this phase and have suboptimal investments and/or poor planning in this area
Besides equipment and machinery-based innovations, there is potential for digital solutions aimed at increasing mineral ore predictability and target optimization, i.e., develop more precise insights into the resource base.

This also includes optimizing maintenance and material flow; monitoring performance; reducing environmental impact and increasing safety.

- Automatically operated drones for monitoring trucks.

- Advanced analytics, i.e., clustering of algorithms to identify causes of failure, for maintenance of trucks.

An important consideration is that innovations, either in terms of equipment and digital solutions, need to adapt to geographical conditions and current infrastructure and (technological, environmental, social) standards.

There is growing scope for digital and other niche technology solutions, e.g., biotechnology, aimed at efficiently managing waste, remediation, rehabilitation, and monitoring activities. Examples:

- Automated monitoring equipment, and drone and virtual reality technology for long-term monitoring.

- Use of genomics-based technologies and biosolids for monitoring and rehabilitation activities.

Source: Author's own elaboration based on Barnett and Lopez (2012), Durrant-Whyte et al. (2015), Lee and Prowse (2014), March Consulting Associates (2012), Monitor Deloitte 2016, S\&P (2017) and Urzua, (2013) for the exploration phase; March Consulting Associates (2012), ScottKemmis (2013), and Supe (2017) for the project development and expansions phase; Barnett and Lopez (2012), Bartos (2007), Deloitte (2017b), Durrant-Whyte et al., (2015), Filippou and King (2011), Lee and Prowse (2014), March Consulting Associates (2012), Stubrin (2017) and Urzua (2013) for the operations phase; Deloitte (2017b), Hiyate (2018), March Consulting Associates (2012) and Urzua (2013) for the closure phase 


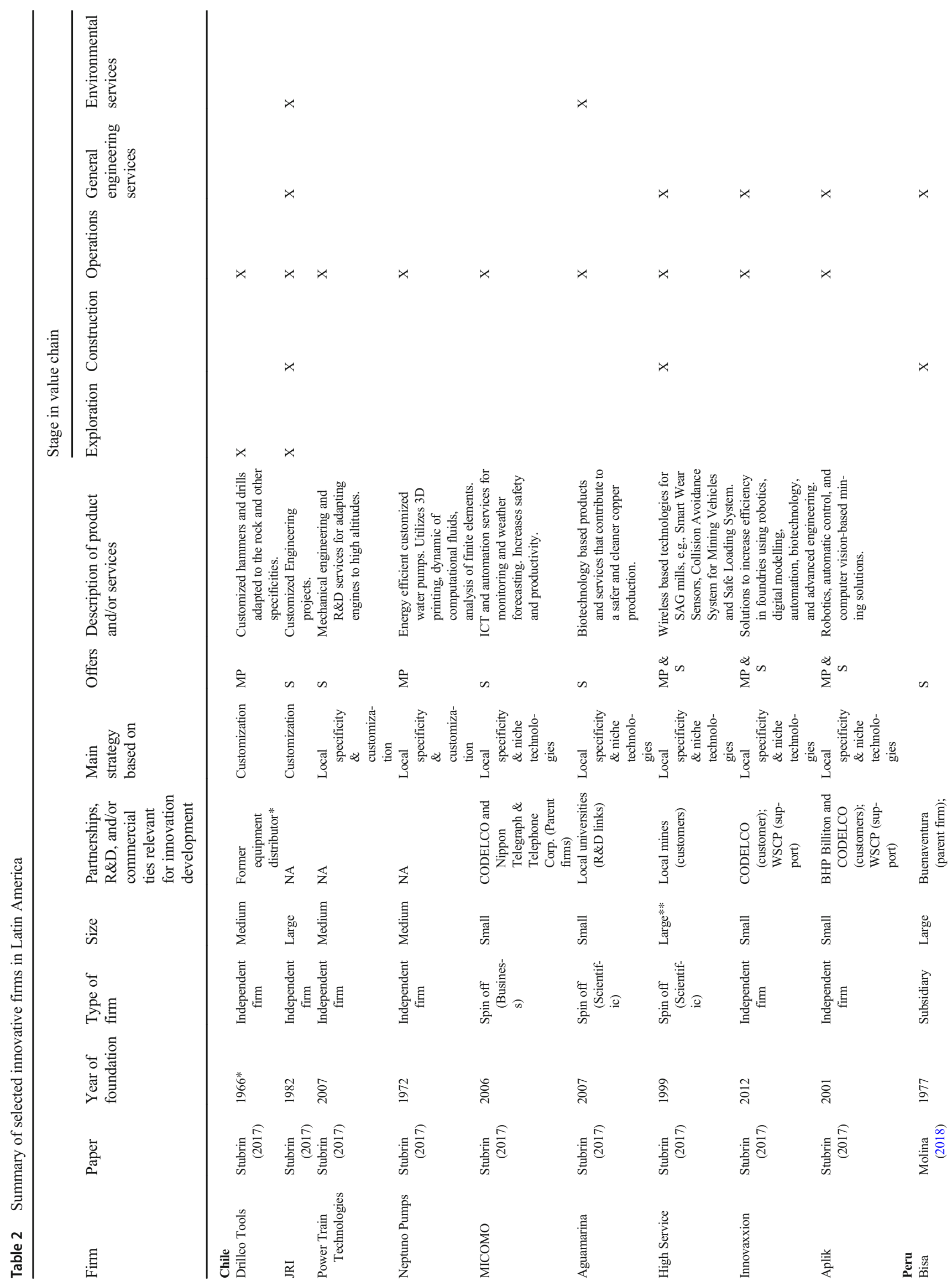




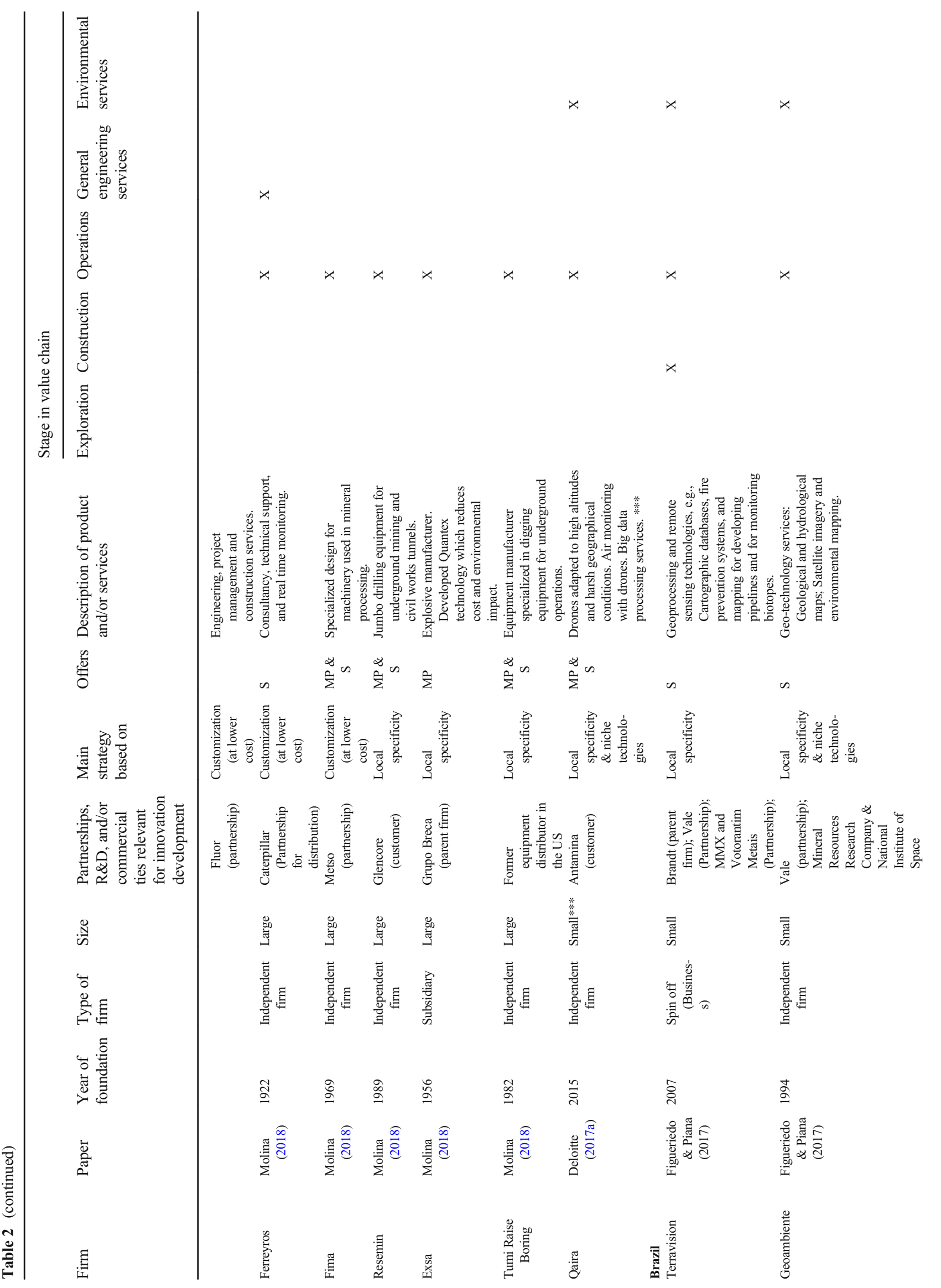




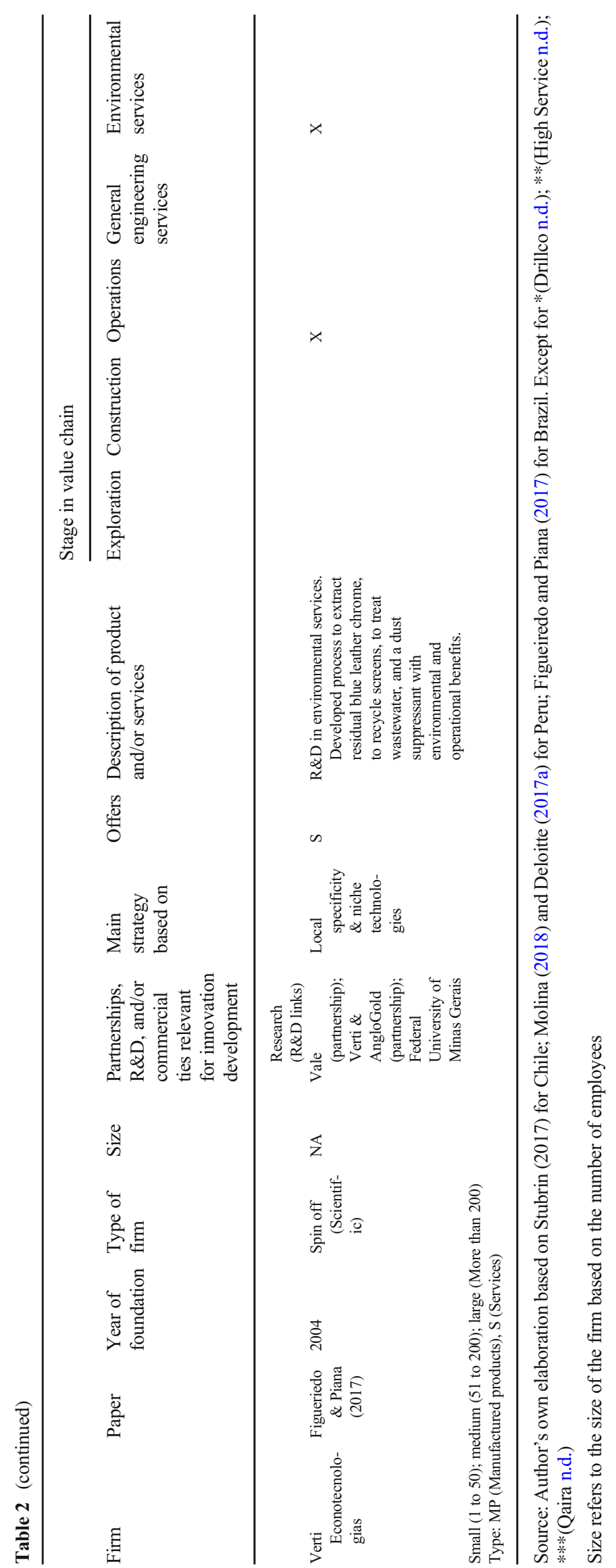


Open Access This article is licensed under a Creative Commons Attribution 4.0 International License, which permits use, sharing, adaptation, distribution and reproduction in any medium or format, as long as you give appropriate credit to the original author(s) and the source, provide a link to the Creative Commons licence, and indicate if changes were made. The images or other third party material in this article are included in the article's Creative Commons licence, unless indicated otherwise in a credit line to the material. If material is not included in the article's Creative Commons licence and your intended use is not permitted by statutory regulation or exceeds the permitted use, you will need to obtain permission directly from the copyright holder. To view a copy of this licence, visit http://creativecommons.org/licenses/by/4.0/.

\section{References}

Barnett R, Lopez L (2012) The rise of the machines. Retrieved from https://spectrum.ieee.org/robotics/industrial-robots/the-rise-of-themachines

Bartos PJ (2007) Is mining a high-tech industry?: investigations into innovation and productivity advance. Res Policy 32(4):149-158. https://doi.org/10.1016/J.RESOURPOL.2007.07.001

Batterham RJ (2004) Has minerals industrial technology peaked? In E. C. Dowling \& J. I. Marsden (Eds.), Improving and Optimizing Operations: Things That Actually Work! (pp. 93-127). Retrieved from https://iteracymethods.wikispaces.com/file/view/10.1.1.126. 1359.pdf

Bechtel (n.d.-a) Accelerating innovation in the EPC Industry - Bechtel. Retrieved March 13, 2018, from http://www.bechtel.com/about-us/ innovation/

Bechtel (n.d.-b). Mining engineering - mining and metals - Bechtel. Retrieved March 13, 2018, from http://www.bechtel.com/services/ mining-metals/

Bryant $\mathrm{P}$ (2015) The case for innovation in the mining industry. Retrieved from http://www.ceecthefuture.org/wp-content/uploads/2016/01/ Clareo_Case-for-Innovation-in-Mining_20150910_lo.pdf

Calzada Olvera B, Foster-McGregor N (2018) What is the potential of natural resource based industrialisation in Latin America? An inputoutput analysis of the extractive sectors (No. \#2018-015). https:// doi.org/10.1111/j.1467-629X.1980.tb00220.x

Campbell JD (1995) Outsourcing in maintenance management. J Qual Maint Eng 1(3):18-24. https://doi.org/10.1108/ 13552519510096369

Crespi G, Katz J, Olivari J (2016) Innovación, actividades basadas en recursos naturales y cambio estructural: la emergencia de empresas de servicios intensivos en conocimientos. In J.C. Navarro \& J. Olivari (Eds.), La Política de Innovación en América Latina y el Caribe. Nuevos Caminos. Retrieved from https://publications.iadb. org/bitstream/handle/11319/7705/La-politica-de-innovacion-enAmerica-Latina-y-el-Caribe-nuevos-caminos.pdf?sequence= 1\&isAllowed=y

de Ferranti D, Perry G, Lederman D, Maloney W (2002) From natural resources to the knowledge economy. Retrieved from http:// documents.worldbank.org/curated/en/563331468088167696/pdf/ multi0page.pdf

Deloitte (2015) Innovation in mining Canada 2015. Retrieved from https://www2.deloitte.com/content/dam/Deloitte/global/ Documents/Energy-and-Resources/gx-ca-en-innovation-in-mining. pdf

Deloitte (2017a) Innovation in mining in Latin America 2017. Retrieved from https://www2.deloitte.com/content/dam/Deloitte/global/ Documents/Energy-and-Resources/latin-america-innovation-inmining.pdf
Deloitte (2017b). Tracking the trends 2017. The top 10 trends mining companies will face in the coming year. Retrieved from https:// www2.deloitte.com/content/dam/Deloitte/global/Documents/ Energy-and-Resources/gx-er-tracking-the-trends-2017.pdf

Drillco (n.d.) Drillco - Home. Retrieved March 29, 2018, from http:// www.drillco.com/

Dry RJ, Batterham RJ, Bates CP, Price DP (2002) ATSE Focus Magazine 123

Durrant-Whyte H, Geraghty R, Pujol F, Sellschop R (2015) How digital innovation can improve mining productivity. In McKinsey \& Company Insights. Retrieved from http://www.mckinsey.com/ insights/energy_resources_materials/how_digital_innovation_can improve_mining_productivity

Farooki M (2012) The diversification of the global mining equipment industry_-going new places? Res Policy 37(4):417-424. https:// doi.org/10.1016/J.RESOURPOL.2012.06.006

Figueiredo PN, Piana J (2017) Innovative capability building and learning linkages in knowledge-intensive service SMEs in Brazil's mining industry. Resour Pol (April), 1-13. https://doi.org/10.1016/j. resourpol.2017.10.012

Filippou D, King MG (2011) R\&D prospects in the mining and metals industry. Res Policy 36(3):276-284. https://doi.org/10.1016/J. RESOURPOL.2011.04.001

Fluor (n.d.) Fluor project highlights - engineering \& construction. Retrieved March 13, 2018, from http://www.fluor.com/projects

Gylfason T (2001) Natural resource and economic growth: what is the connection? (No. 530). Munich, Germany

High Service (n.d.) Highservice: Servicios mineros - minería en Chile. Retrieved March 29, 2018, from http://www.highservice.com/ highservice/es/highservice-corp-home/

Hitzman MW (2002) R\&D in a declining industry (mining): support for the development of revolutionary technologies? Technol Soc 24:6368 Retrieved from www.elsevier.com/locate/techsoc

Hiyate A (2018) Why mine closure matters and why it gets ignored. Retrieved March 1, 2018, from Canadian Mining Journal website: http://www.canadianminingjournal.com/features/mine-closurematters-gets-ignored/

Kaplan D (2012) South African mining equipment and specialist services: technological capacity, export performance and policy. Res Policy 37(4):425-433. https://doi.org/10.1016/j.resourpol.2012.06.001

Katz J and Pietrobelli C (2018) Natural resource based growth, global value chains and domestic capabilities in the mining industry. Resources Policy 58(October 2017): 11-20. https://doi.org/10. 1016/j.resourpol.2018.02.001

La Nauze R, Schodde R (2004) Managing technology development in a changing business environment 2004 SME Annual Conference. 2004 SME Annual Conference. Retrieved from http://www. minexconsulting.com/publications/ManagingTechnology Development SME March 2004.pdf

Lala A, Moyo M, Rehbach S, Sellschop R (2015) Productivity in mining operations: reversing the downward trend

Lee J, Prowse K (2014) Miningand metals + internet of things: industry opportunities and innovation. Retrieved from https:/www.marsdd. com/wp-content/uploads/2014/11/Mining-Metals-and-IoT.pdf

Levesque M, Millar D, Paraszczak J (2014) Energy and mining - the home truths. J Clean Prod 84(1):233-255. https://doi.org/10.1016/ j.jclepro.2013.12.088

Lima AT, Mitchell K, O'Connell DW, Verhoeven J, Van Cappellen P (2016) The legacy of surface mining: remediation, restoration, reclamation and rehabilitation. Environ Sci Pol 66:227-233. https://doi. org/10.1016/J.ENVSCI.2016.07.011

March Consulting Associates (2012) How to successfully access the mining supply chain (p. 50). p. 50. Saskatchewan Ministry of Economy

Molina O (2018) Innovation in an unfavorable context: local mining suppliers in Peru. Res Policy 58(2018):34-48. https://doi.org/10. 1016/j.resourpol.2017.10.011 
Monitor Deloitte (2016) Business ecosystems in exploration. Retrieved from http://www.pdac.ca/docs/default-source/priorities/ geosciences/2016-ecosystems-in-exploration.pdf?sfvrsn= 3f90ba98_2

Morris M, Kaplinsky R, Kaplan D (2012) “One thing leads to another"commodities, linkages and industrial development. Res Policy 37(4):408-416. https://doi.org/10.1016/J.RESOURPOL.2012.06. 008

Navarro L (2017) The World Class Supplier Program for mining in Chile: assessment and perspectives. Resourc Pol (April), 1-13. https://doi. org/10.1016/j.resourpol.2017.10.008

Nieponice G, Vogt T, Koch A (2016). Value creation in mining 2016: Restoring investor confidence. Retrieved from http://image-src.bcg. com/Images/BCG-Restoring-Investor-Confidence-Dec-2016_ tcm9-142726.pdf

OECD. (2011). Classification of manufacturing industries into categories based on R\&D intensities. Retrieved from http://www.oecd.org/sti/ inno/48350231.pdf

Pavitt K (1984) Sectoral patterns of technical change: towards a taxonomy and a theory. Res Policy 13(6):343-373. https://doi.org/10.1016/ 0048-7333(84)90018-0

Perez C, Marin A, Navas-Aleman L (2009) The possible dynamic role of natural resource-based networks in Latin American development strategies. https://doi.org/10.4337/9781782548683.00018

Peterson DJ, LaTourrette T, Bartis JT (2001) New forces at work in mining: industry views of critical technologies. Retrieved from http://www.rand.org/pubs/monograph_reports/MR1324/index.html

Pietrobelli C, Marin A, Olivari J (2018) Innovation in mining value chains : new evidence from Latin America. Resour Pol 1-21

Porter ME (1980) Competitive strategy. Techniques for analyzing industries and competitors : with a new introduction, pp. 1-422. https:// doi.org/10.1002/jsc.540

Prieto B (2009) The engineering and construction industry innovation deficit: is the E\&C Industry model broken? (No. 50). Retrieved from https://gpc.stanford.edu/sites/default/files/wp050_0.pdf

Qaira (n.d.). qAIRa. Retrieved March 29, 2018, from http://www. qairadrones.com/index.php?r=site/productos

Ramos J (1998) A development strategy founded on natural resourcebased production clusters. CEPAL Rev 66:105-128

Rosenfeld Sweeting A, Clark A (2000) Lightening the lode a guide to responsible large-scale mining. Retrieved from https://www. conservation.org/publications/Documents/CI_Policy-Center_ Lightening-the-Lode-a-Guide-to-Responsible-Large-scale-Mining. pdf

S\&P (2017) Worldwide mining exploration trends

Schodde R (2003) Long term trends in exploration and the likely and the likely future of the future of the Australian Exploration Industry. AusIMM Technical Meeting Technical Meeting Melbourne Branch May 2003. Retrieved from https://www.ausimm.com.au/ content/docs/rschodde190503.pdf

Scott-Kemmis D (2013) How about those METS? Leveraging Australia's mining equipment, technology and services sector. Retrieved from http://www.minerals.org.au/file_upload/files/publications/mca how about those METS FINAL.pdf
Smith K (2005) Measuring innovation (Jan Fagerberg \& David C. Mowery, Eds.). https://doi.org/10.1093/oxfordhb/9780199286805. 003.0006

SRK Consulting (2012) Mine and facility closure trends. Retrieved from https://www.srk.com/files/File/newsletters/SRKnews45-facilityclosure-A4.pdf

Stork (n.d.) Stork-mining. Retrieved March 13, 2018, from https:// www.stork.com/en/markets-references/mining

Stubrin L (2017) Innovation, learning and competence building in the mining industry. The case of knowledge intensive mining suppliers (KIMS) in Chile. Resources Policy, 54(October), 167-175. https:// doi.org/10.1016/j.resourpol.2017.10.009

Supe A (2017) "EPCM 4.0"- - the next big thing in engineering and construction-Capgemini Worldwide. Retrieved March 2, 2018, from Capgemini Consulting website: https:/www.capgemini.com/ 2017/12/epcm-4-0-the-next-big-thing-in-engineering-andconstruction/

Taalbi J (2017) What drives innovation? Evidence from economic history. Res Policy 46(8):1437-1453. https://doi.org/10.1016/j.respol. 2017.06.007

Thompson J (2015) Mining - the innovation challenge | World Economic Forum. Retrieved November 23, 2017, from https:/www.weforum. org/agenda/2015/08/mining-\%25e2\%2588\%2592-the-innovationchallenge/

Tilton JE (2014) Cyclical and secular determinants of productivity in the copper, aluminum, iron ore, and coal industries. Miner Econ 27(1). https://doi.org/10.1007/s13563-014-0045-9

Upstill G, Hall P (2006) Innovation in the minerals industry: Australia in a global context. Res Policy 31(3):137-145. https://doi.org/10.1016/J. RESOURPOL.2006.12.002

Urzua O (2013) The emergence and development of knowledge intensive mining service suppliers in the late 20th century. https://doi.org/10. 13140/RG.2.1.4802.0328

Warhurst A, Bridge G (2003) Economic liberalization, innovation and technology transfer: opportunities for cleaner production in copper mining and. In Technological Change and the Environmental Imperative (pp. 11-43). https://doi.org/10.4337/9781781009819. 00007

Wells H (1976) The investment decision under uncertainty. J South Afr Inst Min Metall 9:375 Retrieved from https://www.saimm.co.za/ Journal/v076n09p375.pdf

Wright G, Czelusta J (2003) Mineral resources and economic development. Prepared for the Conference on Sector Reform in Latin America Stanford Center for International Development November 13-15, 2003 . Retrieved from http://www-siepr. stanford.edu/workp/swp04004.pdf

Wright G, Czelusta J (2004) The myth of the resource curse. Challenge 47(2):6-38 Retrieved from https://web.stanford.edu/ write/papers/ WrightResCurse.pdf

Zhu Z, Hsu K, Lillie J (2001) Outsourcing - a strategic move: the process and the ingredients for success. Manag Decis 39(5):373-378. https://doi.org/10.1108/EUM0000000005473

Publisher's note Springer Nature remains neutral with regard to jurisdictional claims in published maps and institutional affiliations. 